\title{
Metode Simple Additive Weighting (SAW) Untuk Menentukan Karyawan Outsourching Terbaik Di PT Bank BNI Cabang Cirebon
}

\author{
Reimond Hasangapan Mikkael Napitupulu ${ }^{1}$, Cucu Handayani ${ }^{2}$, Haryati Haryati ${ }^{3,}$ \\ ${ }^{1}$ Manajemen; Universitas Bina Insani; Jln. Raya Siliwangi No. 6 Rawa Panjang Kota Bekasi, \\ telp (021) 82436886; e-mail: reimond@binainsani.ac.id \\ ${ }^{2}$ Teknik Informatika; STIKOM POLTEK Cirebon; JI. Pusri No.01, Kedawung, Cirebon, telp \\ (0231) 486475; e-mail: de2handayani@gmail.com \\ ${ }^{3}$ Sistem Informasi; STMIK WIT Cirebon; Jl. Ariodinoto 14, Cirebon, telp (0231) 207847; e-mail: \\ haryati.thio@gmail.com \\ * Korespondensi: e-mail: haryati.thio@gmail.com
}

Diterima: 30 September 2021; Review: 29 Nopember 2021; Disetujui: 30 Nopember 2021

Cara sitasi: Napitupulu RHM, Handayani C, Haryati H. 2021. Metode Simple Additive Weighting (SAW) Untuk Menentukan Karyawan Outsourching Terbaik Di PT Bank BNI Cabang Cirebon. Bina Insani ICT Journal. Vol. 8 (2): 166-175.

\begin{abstract}
Abstrak: Penelitian ini bertujuan membangun sebuah sistem pendukung keputusan yang mempunyai kemampuan menghitung nilai kinerja karyawan outsourching untuk menentukan karyawan outsouching terbaik dengan menggunakan metode Simple Additive Weighting (SAW), yang diterapkan menggunakan bahasa pemrograman PHP serta database phpmyadmin. Dalam penilaian kinerja karyawan outsourching di Bank BNI Cabang Cirebon terdapat beberapa kriteria yang menjadi penilaian. Penilaian ini berdasarkan penilaian kehadiran, motivasi kerja, komunikasi \& kerjasama, pemahaman pekerjaan, pengembangan diri, pencapaian target kerja. Hasil dari penilaian tersebut dapat digunakan sebagai pendukung keputusan-keputusan tertentu oleh manajemen Bank BNI Cabang Cirebon terhadap para karyawan outsourching. Dengan aplikasi yang dirancang ini diharapkan dapat memudahkan manajemen Bank BNI Cabang Cirebon dalam melakukan penilaian kinerja terhadap karyawannya. Sehingga hasil dari penilaian tersebut dapat membantu manajemen Bank BNI Cabang Cirebon dalam mengambil suatu keputusan seperti memberikan penghargaan terhadap karyawan terbaik.
\end{abstract}

Kata kunci: karyawan, kinerja, outsourching, SAW, SPK

Abstract: This study to build a decision support system that has the ability to calculate the performance value of outsourcing employees to determine the best outsouching employees using the Simple Additive Weighting (SAW) method, which is applied using the PHP programming language and the phpmyadmin database. In the performance appraisal of outsourcing employees at Bank BNI Cirebon Branch, there are several criteria that become the assessment. This assessment is based on an assessment of attendance, work motivation, communication \& cooperation, understanding of work, self-development, achievement of work targets. The results of the assessment can be used to support certain decisions by the management of Bank BNI Cirebon Branch for outsourcing employees. With this designed application, it is hoped that it can facilitate the management of Bank BNI Cirebon Branch in assessing the performance of its employees. So that the results of the assessment can help the management of Bank BNI Cirebon Branch in making decisions such as giving awards to the best employees. 
Keywords: DSS, employees, outsourcing, performance, SAW

\section{Pendahuluan}

Meskipun kondisi ekonomi sedang bergejolak, dunia usaha atau bisnis saat ini sedang berkembang dan menurun. Dalam hal ini mempengaruhi persaingan dalam dunia usaha baik di pasar domestik maupun internasional. Pasar-pasar ini menunjukkan persaingan yang semakin penting, dan setidaknya untuk mendapatkan pangsa pasar, semua perusahaan harus selalu menonjol dari persaingan. Menjaga kelangsungan bisnis. Dalam kompetisi yang belum pernah terjadi sebelumnya. Salah satu cara untuk mempertahankan status bisnis Anda adalah dengan memberikan panduan, pelatihan, dan perhatian yang lebih detail terhadap kualitas produk yang dihasilkan perusahaan Anda.

Industri perbankan saat ini berkembang sangat pesat, bahkan hampir di setiap daerah dan setiap jalan terdapat cabang-cabang bank. Hal yang sama berlaku untuk PT. Bank Negara Indonesia (Persero) Tbk atau Bank BNI cabang Cirebon memiliki beberapa cabang dan kantor kas di dalam dan sekitar Cirebon. Bank BNI cabang Cirebon memiliki jumlah pegawai yang cukup banyak, baik pegawai tetap maupun pegawai outsourcing. Setiap karyawan memiliki tanggung jawab dan tanggung jawab sesuai dengan posisinya. Ini harus diisi dan dilaporkan secara teratur. Hasil kinerja pegawai merupakan dasar untuk menilai prestasi kerja. Jika kinerjanya baik, akan diberikan bonus, dan jika kinerjanya buruk, akan diberikan sanksi sesuai ketentuan yang berlaku.

Kinerja pegawai merupakan hasil kerja kualitatif dan kuantitatif yang dilakukan oleh pegawai sesuai dengan tugas [1] yang diberikan menurut Susilo sendiri. Penilaian kinerja karyawan pada dasarnya adalah penilaian yang sistematis terhadap kinerja dan potensi seorang karyawan dalam proses kerja intensif yang sedang dikembangkan untuk kepentingan perusahaan atau organisasi [2]. Di sisi lain, dalam teori pribadi saya, kinerja adalah hasil dari apa yang dilakukan seseorang saat melakukan suatu aktivitas atau tugas. Kinerja adalah hasil atau tingkat keberhasilan melakukan tugas Anda secara keseluruhan selama periode waktu tertentu. Ini ditetapkan dan disepakati bersama terhadap berbagai pilihan seperti standar kerja, tujuan, sasaran dan standar. Kinerja adalah terjemahan dari kata kinerja, dan akar kata "eksekusi" mengandung beberapa "item". (1) Eksekusi, operasi, eksekusi (atau eksekusi, eksekusi). (2) Pemenuhan atau pemenuhan kewajiban atau niat atau sumpah (pemenuhan; sebagai sumpah); (3) Memenuhi atau meningkatkan kewajiban (memenuhi; memenuhi sebagai sumpah); (4) Melakukan apa yang diharapkan dari seseorang atau mesin (melakukan apa yang diharapkan dari orang-mesin) [3]

Laporan kinerja pegawai akan terus dibuat secara online dari website Bank BNI. Semua karyawan incumbent dapat melaporkan kinerjanya setiap triwulan pada akhir bulan, mengisi dan menyerahkan pada halaman pelaporan. Dibuat secara manual. Menurut laporan tersebut, Anda dapat melihat akurasi, kesalahan, disiplin, kecepatan, dan tingkat layanan. Selain laporan, kasir juga memiliki kuesioner yang diisi oleh pelanggan yang melakukan transaksi di kasir. Formulir yang masih diproses secara manual dapat bersifat subjektif karena evaluasi dilakukan oleh atasan sendiri, karena sulitnya mendapatkan informasi secara cepat ketika menilai kinerja individu terutama kasir. Oleh karena itu, diperlukan sistem penilaian yang terukur untuk mengetahui kinerja pegawai, khususnya pada pegawai outsourcing. Munculnya outsourcing sebagai siklus bisnis lebih pendek. Jika terjadi gejolak eksternal (termasuk siklus krisis), perusahaan dengan ribuan karyawan terlalu berisiko. Manajemen, sementara itu, mengajarkan bahwa perusahaan yang sukses adalah mereka yang fokus pada kompetensi inti. Perusahaan tidak ingin terlalu khawatir tentang berada di luar kendali. Outsourcing membantu perusahaan meningkatkan efisiensi proses produksi mereka. Misalnya, sebuah perusahaan pertambangan besar menjadikan pertambangan sebagai bisnis inti tanpa memikirkan kembali kebersihan lingkungan atau bagaimana bangunan perusahaan dan bagaimana menanggapi lingkungan. Keamanan perusahaan. Untuk hal-hal yang bukan merupakan bagian dari bisnis inti perusahaan, Anda dapat membuat kontrak dengan penyedia layanan atau perusahaan outsourcing [4].

Bank BNI Cirebon mempekerjakan total 207 orang, 96 di antaranya full-time dan 111 di antaranya outsourcing. Perbandingan kuantitatif menunjukkan bahwa jumlah pegawai outsourcing lebih dari separuh jumlah pegawai tetap atau total tenaga kerja bank Cirebon. Karyawan outsourcing memegang berbagai posisi, mulai dari kasir, penjualan atau pemasaran, keamanan, teknisi, pengemudi hingga layanan kebersihan. Mengingat bahwa loket bank adalah 
salah satu posisi kunci dan pemimpin dalam kualitas layanan pelanggan, sistem penilaian kinerja staf outsourcing berfokus pada loket.

Decision Support System (DSS) atau Sistem Pendukung Keputusan (DSS) adalah sistem informasi interaktif yang menyediakan informasi, pemodelan, dan data operasional untuk membantu pengambilan keputusan dalam situasi semi-terstruktur di mana tidak ada yang tahu bagaimana membuat keputusan. DSS dirancang untuk menginformasikan, mengarahkan, mengantisipasi, dan memandu pengguna yang terinformasi untuk membuat keputusan yang lebih baik. DSS adalah implementasi dari teori keputusan yang diperkenalkan dalam sains seperti riset operasi dan manajemen. Satu-satunya perbedaan adalah bahwa di masa lalu Anda harus melakukan perhitungan berulang secara manual untuk menemukan solusi dari masalah yang dihadapi (biasanya untuk menemukan minimum dan maksimum atau maksimum). Komputer PC sekarang menawarkan kemungkinan untuk memecahkan masalah yang sama dalam waktu yang relatif singkat.

Perancangan sistem evaluasi kinerja pegawai outsourcing ini menggunakan metode penjumlahan sederhana (SAW), atau lebih dikenal dengan metode penjumlahan berbobot. SAW merupakan metode pendukung keputusan yang banyak digunakan di berbagai bidang [5]. Penerapan metode SAW bertujuan untuk menjadi alat untuk mengidentifikasi karyawan outsourcing terbaik berdasarkan kriteria kinerja tertentu. Kriteria kinerja teller meliputi ketepatan, kesalahan, kedisiplinan, kecepatan, dan pelayanan. Metode penambahan bobot sederhana (SAW) membutuhkan proses untuk menormalkan matriks keputusan (X) ke skala yang dapat dibandingkan dengan semua evaluasi alternatif yang tersedia.

Penelitian sebelumnya telah membahas kombinasi metode ranking centroid (ROC) dan simple weighting (SAW) untuk membuat keputusan manajer perusahaan saat menilai kinerja karyawan [6]. Dengan dukungan sistem pendukung keputusan yang digunakan, hasil evaluasi pegawai seharusnya lebih efektif dan objektif. Banyak penelitian menggunakan metode pembobotan aditif sederhana untuk menilai kinerja, tetapi dengan atau tanpa pembobotan yang tepat. Dikombinasikan dengan metode pembobotan dan pemeringkatan, hasil keputusan dapat ditentukan lebih efektif [7]. Evaluasi pegawai juga merupakan aplikasi berbasis web yang membandingkan metode TOPSIS dan SAW agar proses evaluasi lebih efektif dan efisien [8].

Penambahan sederhana (SAW), yang memiliki beberapa kriteria kualitas kerja, kapasitas kerja, disiplin kerja, tanggung jawab, dan kerjasama, mengambil data yang dinormalisasi $(R)$ dan dikalikan dengan $(R)$ sehingga akan memberikan hasil akhir. Apa yang diperhitungkan untuk mendapatkan nilai terbaik dari hasil pemeringkatan dipilih sebagai pilihan terbaik (Ai) untuk menilai kinerja pegawai [9]. Ada lima kriteria untuk mengukur kinerja karyawan: disiplin kerja, pendidikan terkini, pengalaman kerja, kerjasama dan semangat. Sistem ini menggunakan metode Simple Additive Weighting (SAW), yaitu metode pembobotan berdasarkan bobot standar yang dibagi menjadi bobot standar (yaitu pendapatan) dan bobot standar (yaitu biaya) [10]. Penambahan sederhana (SAW), yang memiliki beberapa kriteria kualitas kerja, kapasitas kerja, disiplin kerja, tanggung jawab, dan kerjasama, mengambil data yang dinormalisasi $(R)$ dan dikalikan dengan $(R)$ sehingga akan memberikan hasil akhir. Apa yang diperhitungkan untuk mendapatkan nilai terbaik dari hasil pemeringkatan dipilih sebagai pilihan terbaik ( $\mathrm{Ai}$ ) untuk menilai kinerja pegawai [9]. Ada lima kriteria untuk mengukur kinerja karyawan: disiplin kerja, pendidikan terkini, pengalaman kerja, kerjasama dan semangat. Sistem ini menggunakan metode Simple Additive Weighting (SAW), yaitu metode pembobotan berdasarkan bobot standar yang dibagi menjadi bobot standar (yaitu pendapatan) dan bobot standar (yaitu biaya) [10]. Selain metode SAW, Anda juga dapat memilih metode TOPSIS. Hal ini karena sangat membantu dalam pengambilan keputusan saat menilai kinerja pegawai [11]. Seiring berjalannya waktu, perkembangan teknologi begitu pesat sehingga ilmu ekonomi dan teknologi semakin maju, sehingga masyarakat perlu mengikuti perkembangan tersebut terutama dalam bekerja. Tetapi bagaimana jika karyawan tidak melakukan pekerjaan mereka dengan benar. Selama ini evaluasi karyawan masih dilakukan secara manual, perlu waktu untuk menentukan nilai, dan jumlah karyawan yang bekerja di perusahaan tidak sedikit. Metode Simple Additive Weighting dapat diterapkan pada proses penilaian kinerja karyawan dan sesuai dengan penelitian yang dilakukan oleh Siagian bahwa penilaian kinerja menggunakan Metode Simple Additive Weighting sangat mempermudah perusahaan dalam pengelolaan data kinerja karyawan [17], aplikasi yang dibuat menghasilkan informasi nilai karyawan yang lebih beragam, dan dapat digunakan oleh perusahaan sebagai pendukung keputusan-keputusan tertentu sesuai dengan penelitian yang dilakukan oleh Takrim dengan menggunakan aplikasi dapat 
mempermudah serta mempercepat dalam penilaian kinerja karyawan [18]. Peneliti membuat aplikasi berbasis web yang membandingkan metode Topsis dan SAW agar proses evaluasi lebih efektif dan efisien.

\section{Metode Penelitian}

Metode SAW juga dikenal sebagai metode penambahan berbobot. Konsep dasar metode SAW adalah mencari penjumlahan terbobot dari evaluasi kinerja setiap pilihan semua atribut [12]. Metode Simple Additive Weighting (SAW) juga dikenal sebagai metode pembobotan. Konsep dasar metode SAW adalah mencari penjumlahan terbobot dari evaluasi kinerja setiap pilihan semua atribut. Metode SAW perlu menormalkan matriks keputusan (X) ke skala yang dapat dibandingkan dengan semua evaluasi kandidat yang tersedia. Metode SAW membutuhkan proses normalisasi matriks keputusan $(X)$ yang skalanya dapat dibandingkan dengan semua alternatif penilaian yang ada [13]. Metode pembobotan aditif sederhana (SAW) juga biasa disebut sebagai pembobotan aditif. Konsep dasar dari simple weighted weighting (SAW) adalah menentukan jumlah bobot evaluasi kinerja dari setiap pilihan setiap atribut. Metode pembobotan sederhana (SAW) perlu menormalkan matriks keputusan (X) ke skala yang dapat dibandingkan dengan semua evaluasi alternatif yang tersedia [14].

$$
r_{i j}=\left\{\begin{array}{l}
\frac{X_{i j}}{\operatorname{Max} x_{i j}} \\
\frac{M i n}{i} x_{i j} \\
\frac{i}{X_{i j}}
\end{array}\right.
$$

jika $j$ adalah atribut keuntungan (benefit)

Dengan $r_{i j}$ adalah rating kinerja ternormalisasi dari alternative $A_{i}$ pada atribut $C_{j} ; i=1,2, \ldots m$ dan $\mathrm{j}=1,2, \ldots \mathrm{n}$.

Nilai preferensi untuk setiap alternatif $\left(\mathrm{V}_{\mathrm{i}}\right)$ diberikan sebagai:

$$
V_{i}=\sum_{j=1}^{n} W_{j} r_{i j}
$$

Nilai $V_{i}$ lebih besar mengindikasikan bahwa alternatif $A_{i}$ lebih terpilih.

Model penilaian pegawai Bank BNI Cabang Cirebon ini dikembangkan dengan menggunakan metode pembobotan sederhana. Saat menggunakan metode pembobotan sederhana, ada beberapa langkah untuk menentukan kriteria dan jenisnya (laba/biaya), menentukan bobot preferensi, membuat matriks keputusan, membuat matriks normalisasi, peringkat, dan sebagainya. [15]. Berikut adalah langkah-langkah penerapan metode pembobotan sederhana dalam penilaian kinerja pegawai di BNI cabang Cirebon.

Langkah pertama: menentukan kriteria penilaian beserta bobot preferensi. Pada tahap ini akan digunakan kriteria-kriteria penilaian yang sebelumnya telah diterapkan di bank BNI Cabang Cirebon. Kriteria penilaian yang diterapkan, yaitu: a) Kehadiran karyawan/C1 (benefit), b) Kecepatan Pelayanan/C2 (benefit), c) Akurasi Transaksi/C3 (benefit), d) Proses Layanan/C4 (benefit), e) Aktivitas Cross Selling /C5 (benefit), f) Penerapan Prinsip 46/C6 (benefit).

Langkah kedua: penetapan bobot preferensi, berikut bobot preferensi pada masingmasing kriteria yang akan terapkan: a) Kehadiran karyawan $/ \mathrm{C} 1=2$, b) Kecepatan Pelayanan $/ \mathrm{C} 2=2, \mathrm{c}$ ) Akurasi Transaksi $/ \mathrm{C} 3=1$, d) Proses Layanan $/ \mathrm{C} 4=2$, e) Aktivitas Cross Selling/C5 (benefit) = 1, f) Penerapan Prinsip 46/C6 (benefit) $=2$.

Langkah ketiga: pembentukan matriks keputusan, pada tahap ini diperlukan tabel rating kecocokan. Tabel 1 menampilkan rating kecocokan yang digunakan.

Tabel 1. Tabel Rating Kecocokan

\begin{tabular}{lllllll}
\hline \multirow{2}{*}{ Alternatif } & Kriteria & & & & \\
\cline { 2 - 7 } & C1 & C2 & C3 & C4 & C5 & C6 \\
\hline A1 & 8 & 6 & 7 & 8 & 7 & 7 \\
\hline A2 & 7 & 7 & 6 & 6 & 7 & 7 \\
\hline A3 & 7 & 6 & 7 & 6 & 7 & 6 \\
\hline A5 & 8 & 7 & 7 & 6 & 7 & 6 \\
\hline
\end{tabular}

Sumber: Hasil Penelitian (2021) 
Berikut matriks keputusan berdasarkan tabel rating kecocokan:

$x=\left[\begin{array}{llllll}8 & 6 & 7 & 8 & 7 & 6 \\ 7 & 7 & 6 & 8 & 7 & 7 \\ 7 & 6 & 7 & 6 & 7 & 6 \\ 8 & 7 & 7 & 6 & 7 & 6 \\ 7 & 8 & 6 & 6 & 7 & 6\end{array}\right]$

Langkah keempat: membuat matriks normalisasi, karena semua kriteria-kriteria bersifat benefit maka hasil normalisasinya adalah sebagai berikut:

$R=\left[\begin{array}{llllll}1,0000 & 0,7500 & 1,0000 & 1,0000 & 1,0000 & 0,8571 \\ 0,8750 & 0,8750 & 0,8571 & 1,0000 & 1,0000 & 1,0000 \\ 0,8750 & 0,7500 & 1,0000 & 0,7500 & 1,0000 & 0,8571 \\ 1,0000 & 0,8750 & 1,0000 & 0,7500 & 1,0000 & 0,8571 \\ 0,8750 & 1,0000 & 0,8571 & 0,7500 & 1,0000 & 0,8571\end{array}\right]$

Langkah kelima: melakukan perankingan yang diperoleh dari persamaan, berikut perhitungan perankingan yang dilakukan:

$\mathrm{V} 1=\left(1,0000^{\star} 2\right)+\left(0,7500^{\star} 2\right)+\left(1,0000^{*} 1\right)+\left(1,0000^{\star} 2\right)+\left(1,0000^{*} 1\right)+(0,8571 * 2)=9,2143$

$\mathrm{V} 2=(0,8750 * 2)+(0,8750 * 2)+(0,8571 * 1)+\left(1,0000^{*} 2\right)+\left(1,0000^{*} 1\right)+\left(1,0000^{*} 2\right)=9,3571$

$\mathrm{V} 3=(0,8750 * 2)+(0,7500 * 2)+\left(1,0000^{*} 1\right)+\left(0,7500^{*} 2\right)+\left(1,0000^{*} 1\right)+(0,8571 * 2)=8,4643$

$\mathrm{V} 4=\left(1,0000^{*} 2\right)+\left(0,8750^{\star} 2\right)+\left(1,0000^{*} 1\right)+\left(0,7500^{\star} 2\right)+\left(1,0000^{*} 1\right)+(0,8571 * 2)=8,9643$

$V 5=\left(0,8750^{\star} 2\right)+\left(1,0000^{\star} 2\right)+\left(0,8571^{\star} 1\right)+\left(0,7500^{\star} 2\right)+\left(1,0000^{*} 1\right)+\left(0,8571^{*} 2\right)=8,8214$

Dari hasil perhitungan tersebut dapat kita lihat bahwa nilai maksimum berada pada V2. Oleh karena itu, Alternate A2 dipilih sebagai karyawan dengan kinerja terbaik.

Flowchart digunakan untuk menggambarkan secara grafis desain prosedur untuk digunakan dengan simbol flowchart yang diperlukan. Diagram alir sistem dapat didefinisikan sebagai diagram yang menunjukkan alur kerja sistem secara keseluruhan. Gambar ini menunjukkan urutan langkah-langkah yang ada pada sistem. Diagram alir sistem menunjukkan apa yang terjadi di dalam sistem [16]. Diagram alir proses adalah diagram alir yang banyak digunakan dalam teknik industri. Bagan alir ini juga berguna bagi analis sistem untuk menjelaskan proses prosedur.

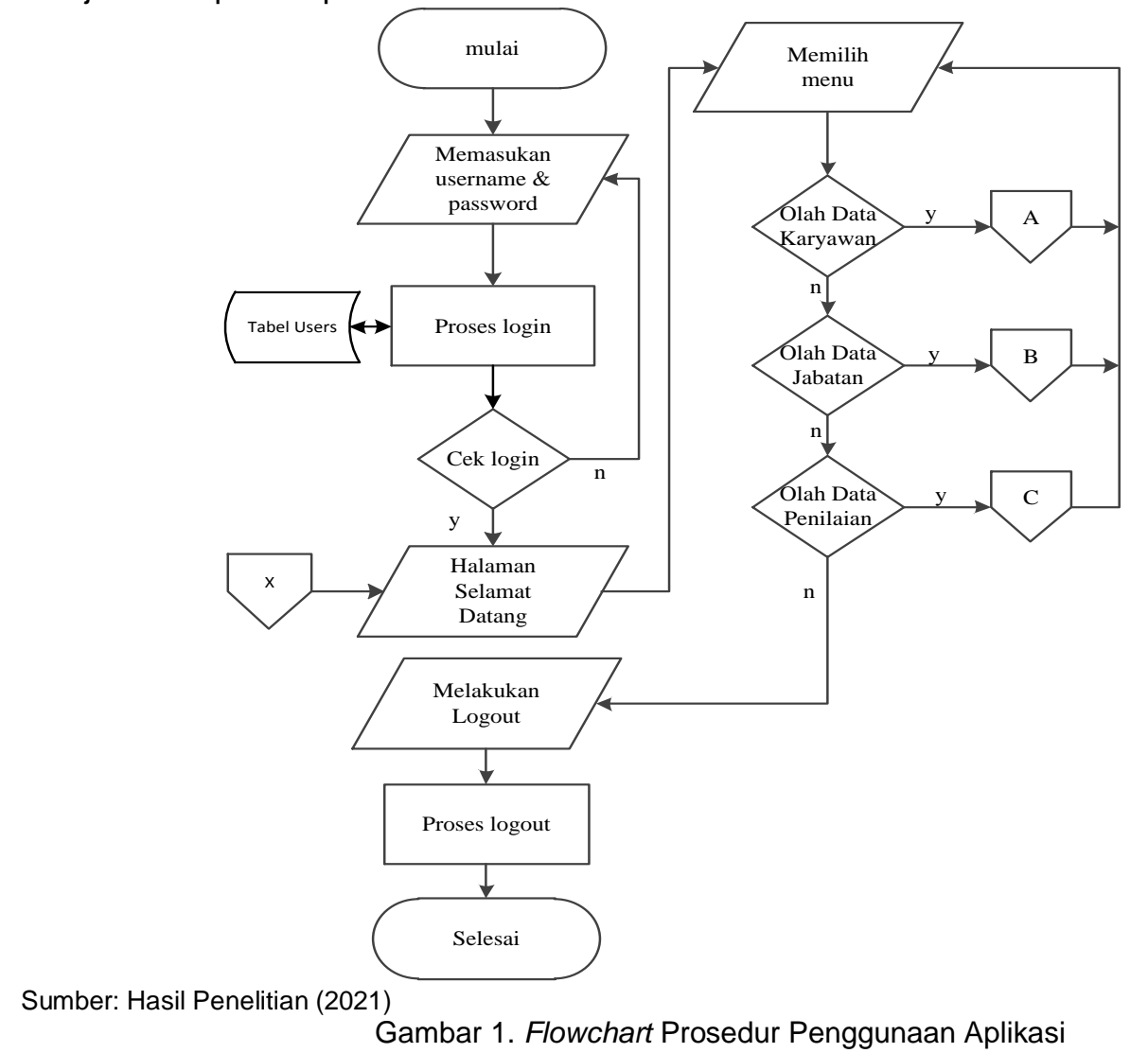


Prosedur penggunaan aplikasi mulai dari memasukkan username dan password lalu proses login yang terhubungan dengan tabel users, lalu pengecekan login jika $\mathrm{N}$ maka akan menampilkan kembali username dan password jika $\mathrm{Y}$ maka akan menampilkan Halaman Selamat Datang. Dilanjutkan dengan memilih menu: 1) olah data karyawan dan dilanjutkan ke pengolahan data karyawan, 2) olah data jabatan dan dilanjutkan ke pengolahan data jabatan, 3) olah data penilaian dan dilanjutkan ke pengolahan data penilaian, 4) melakukan logout dilanjutkan proses logout dan selesai. Flowchart prosedur penggunaan aplikasi dijelaskan pada gambar 1.

Pengolahan data karyawan dilanjutkan dengan memilih proses lalu 1) pilih input dilanjutkan dengan input data karyawan, proses input data karyawan dan validasi data jika $Y$ maka akan disimpan dalam tabel karyawan dan jika tidak $\mathrm{N}$ maka akan menampilkan input data karyawan kembali, 2) pilih edit dilanjutkan dengan edit data karyawan, proses edit data karyawan dan validasi data jika $\mathrm{Y}$ maka akan disimpan dalam tabel karyawan dan jika tidak $\mathrm{N}$ maka akan menampilkan edit data karyawan kembali, 3) pilih hapus dilanjutkan dengan hapus data karyawan, proses hapus data karyawan dan konfirmasi data jika $Y$ maka akan disimpan dalam tabel karyawan dan jika tidak $\mathrm{N}$ maka akan menampilkan hapus data karyawan kembali, 4) Dari tabel karyawan akan dilanjutkan ke pilih proses, 5) jika memilih $\mathrm{N}$ maka akan menampilkan kembali ke menu utama dan $Y$ maka akan menampilkan selamat datang. Flowchart prosedur pengolahan data karyawan dijelaskan pada gambar 2 .

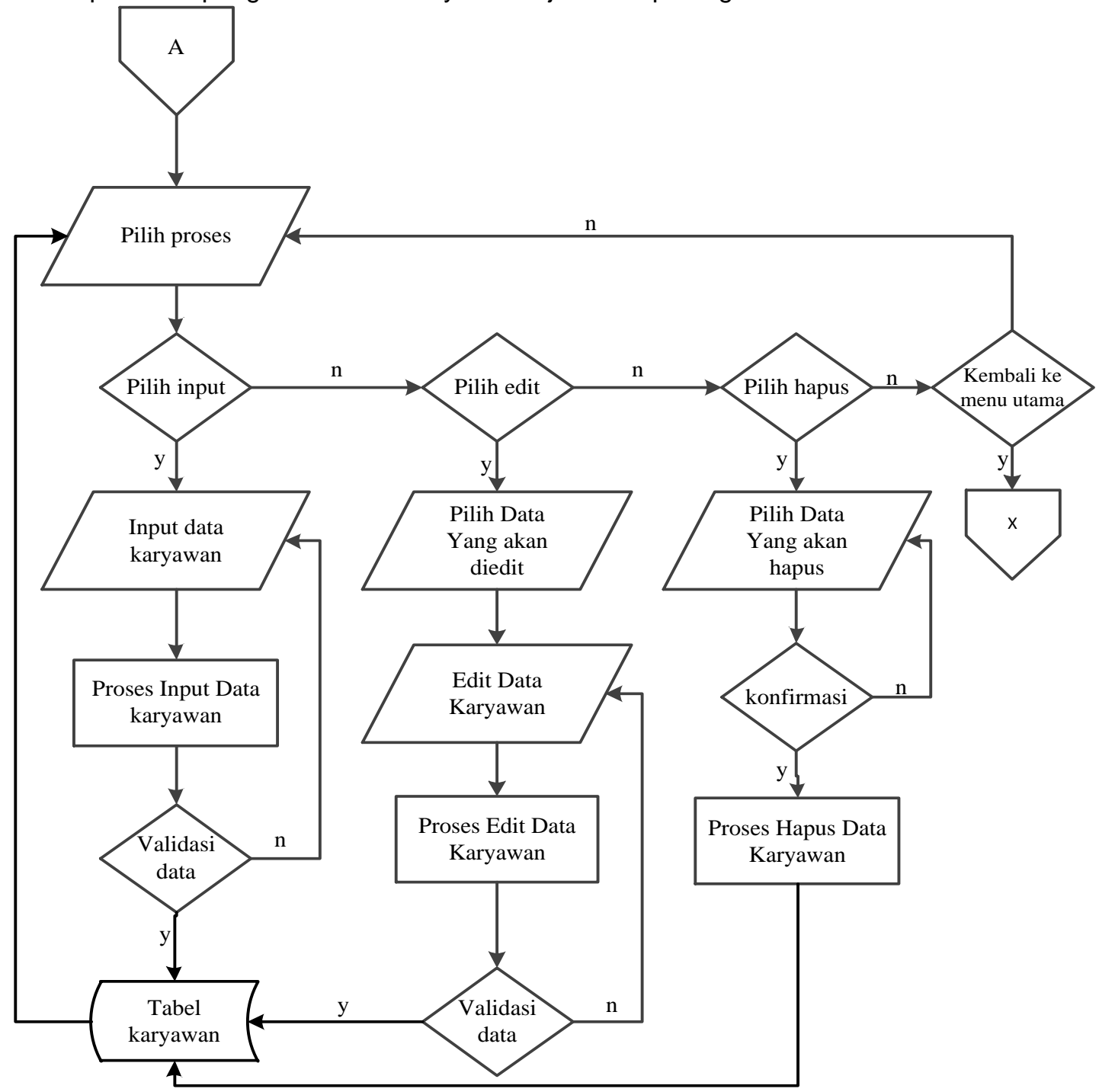

Sumber: Hasil Penelitian (2021)

Gambar 2. Flowchart Prosedur Pengolahan Data Karyawan 
Pengolahan data penilaian dilanjutkan dengan memilih proses lalu 1) pilih input dilanjutkan dengan input data penilaian, proses input data penilaian dan validasi data jika $Y$ maka akan disimpan dalam tabel penilaian dan jika tidak $\mathrm{N}$ maka akan menampilkan input data penilaian kembali, 2) pilih edit dilanjutkan dengan edit data penilaian, proses edit data penilaian dan validasi data jika $\mathrm{Y}$ maka akan disimpan dalam tabel penilaian dan jika tidak $\mathrm{N}$ maka akan menampilkan edit data penilaian kembali, 3) pilih hapus dilanjutkan dengan hapus data penilaian, proses hapus data penilaian dan konfirmasi data jika $Y$ maka akan disimpan dalam tabel penilaian dan jika tidak $\mathrm{N}$ maka akan menampilkan hapus data penilaian kembali, 4) Dari tabel penilaian akan dilanjutkan ke pilih proses, 5) jika memilih $\mathrm{N}$ maka akan menampilkan kembali ke menu utama dan Y maka akan menampilkan selamat datang. Flowchart prosedur pengolahan data penilaian dijelaskan pada gambar 3 .

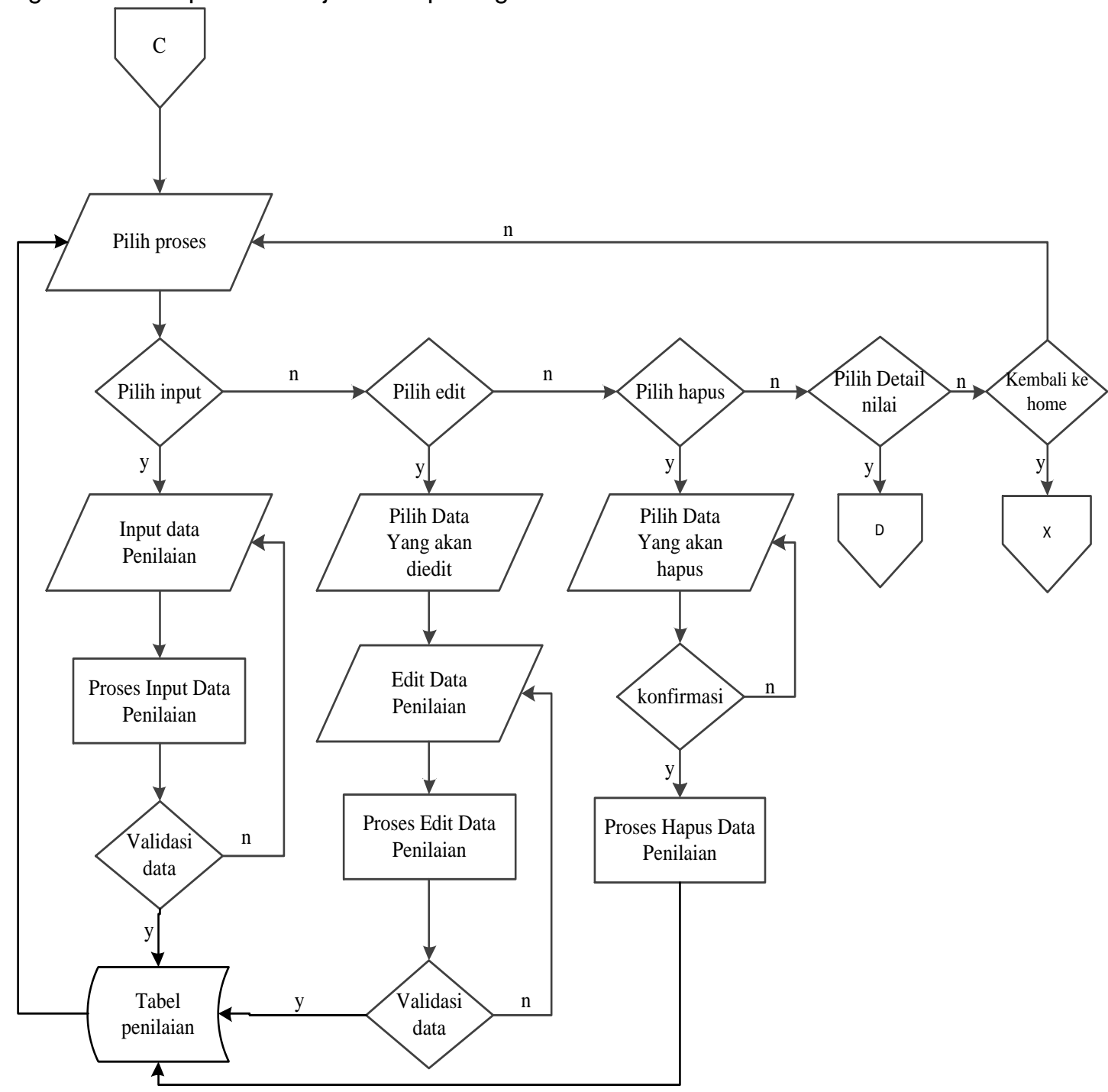

Sumber: Hasil Penelitian (2021)

Gambar 3. Flowchart Prosedur Pengolahan Data Penilaian

\section{Hasil dan Pembahasan}

Untuk menjalankan aplikasi sistem penilaian kinerja karyawan dengan membuka alamat https://penilaiankineria pada web browser, setelah membuka alamat itu akan muncul halaman form login yang harus diisi dengan benar agar dapat mengakses halaman utama aplikasi penilaian kinerja karyawan. Setelah berhasil melakukan login maka akan dialihkan ke halaman selamat datang berikut dan berikutnya untuk mengolah data karyawan pilih menu tabel karyawan, disana kita dapat mengolah data karyawan seperti tambah, edit, dan hapus. Untuk mengolah data jabatan pilih menu tabel jabatan, disana kita dapat mengolah data jabatan 
seperti tambah, edit, dan hapus. Berikut tampilan halaman olah data jabatan dijelaskan pada gambar 4.

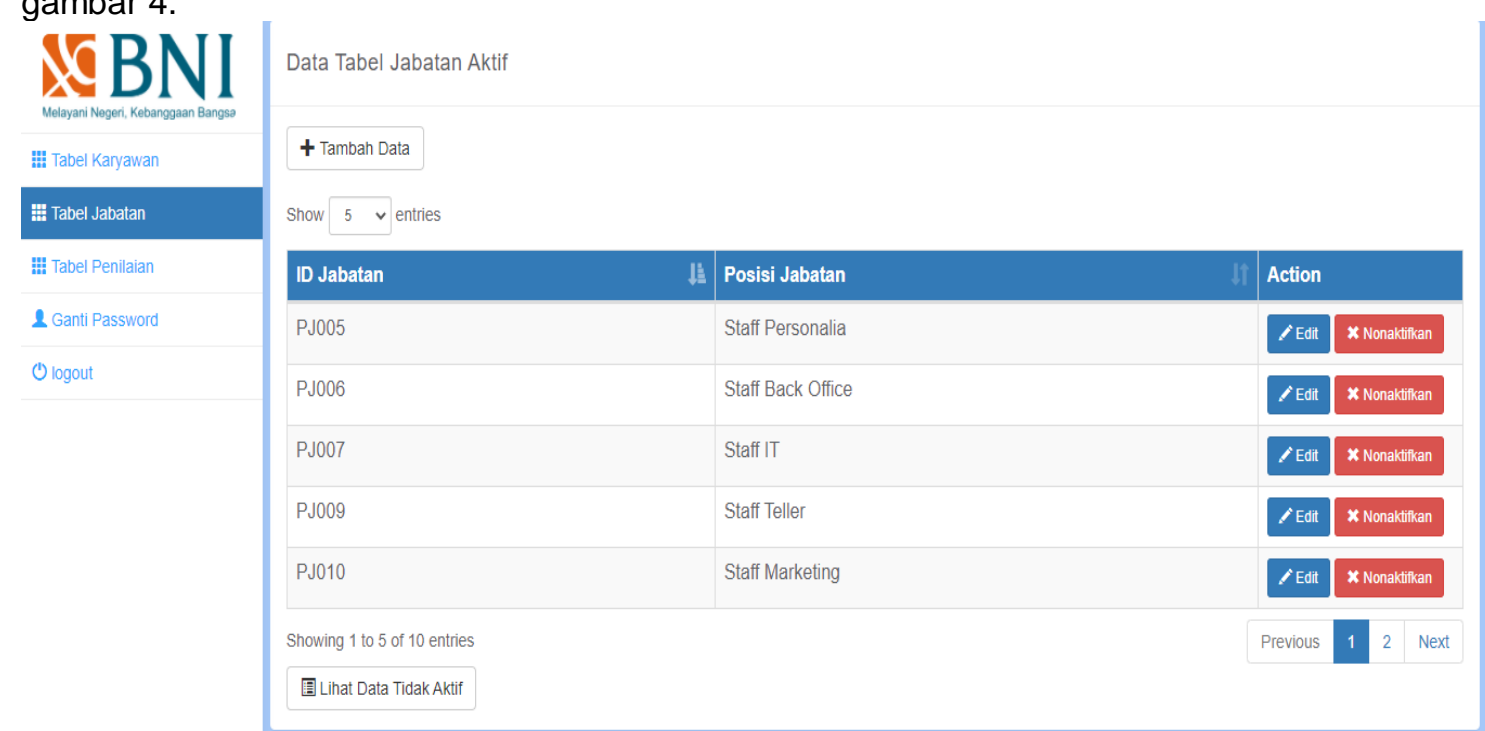

Sumber: Hasil Penelitian (2021)

Gambar 4. Halaman Jabatan

Untuk mengolah data penilaian pilih menu tabel penilaian, disana kita dapat mengolah data penilaian seperti tambah, edit, hapus dan detail. Dalam mengolah detail penilaian pada halaman olah data penilaian klik tombol detail, setelah itu browser akan mengalihkan kehalaman detail penilaian yang sesuai dengan data penilaian yang dipilih. Pada halaman detail penilaian kita bisa mengolah data seperti tambah, edit, hapus. Dan pada halaman ini pula kita dapat melihat tampilan normalisasi, dan ranking yang merupakan hasil dari penerapan metode simple additive weighting pada aplikasi penilaian kinerja karyawan ini.

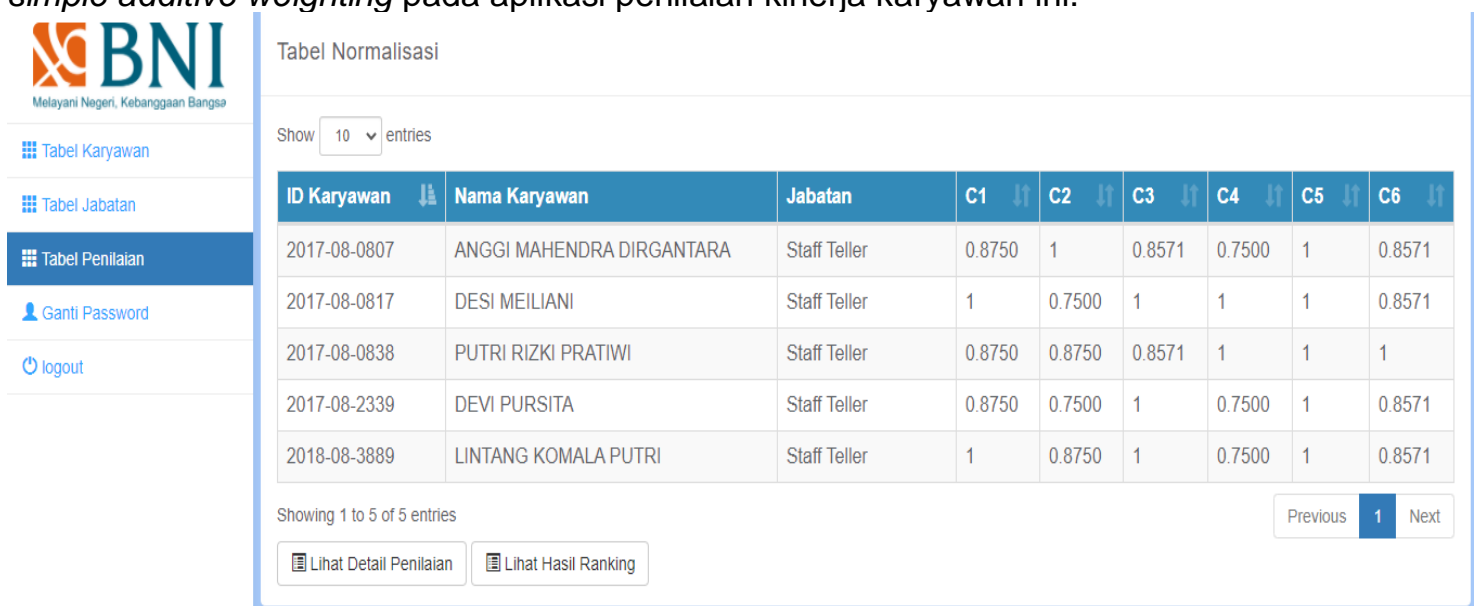

Sumber: Hasil Penelitian (2021)

\section{Kesimpulan}

Gambar 5. Halaman Perhitungan

Berdasarkan evaluasi dan uji coba aplikasi sistem penilaian kinerja karyawan menggunakan metode Simple Additive Weighting, dapat disimpulkan bahwa metode Simple Additive Weighting berdasarkan penetapan bobot preferensi dengan kriteria: a) Kehadiran karyawan/C1, b) Kecepatan Pelayanan/C2, c) Akurasi Transaksi/C3, d) Proses Layanan/C4, e) 
Aktivitas Cross Selling/C5 (benefit), dan f) Penerapan Prinsip 46/C6 (benefit) dengan didukung menu tabel karyawan, menu tabel jabatan, menu tabel penilaian dan menu ganti password yang mana juga terdapat fitur pada ketiga menu tersebut dalam menampilkan data, input data, edit data dan hapus data yang sangat membantu pimpinan PT. Bank BNI cabang Cirebon dalam memperoleh hasil dari kinerja karyawan agar dapat mempercepat penilaian kinerja yang akurat dengan tujuan untuk mempermudah dalam menetapkan reward maupun punishment untuk karyawan di PT. Bank BNI cabang Cirebon.

\section{Referensi}

[1] R. Akbar, D. Prasetiyani, and Nariah, "Pengaruh Motivasi Terhadap Kinerja Karyawan Pada PT. Unggul Abadi Di Jakarta," J. Ekon. Ef., vol. 3, no. 1, pp. 84-90, 2020, doi: http://dx.doi.org/10.32493/JEE.v3i1.7317.

[2] S. Purba, "Pengaruh Budaya Organisasi, Modal Intelektual dan Perilaku Inovatif terhadap kinerja Pemimpin Jurusan di Universitas Negeri Medan," J. Bisnis dan Ekon., vol. 13, no. 2, pp. 150-167, 2009, doi: https://doi.org/10.24002/kinerja.v13i2.37.

[3] Wibowo, Manajemen Kinerja. Jakarta: Rajawali Pers, 2017.

[4] S. H. Tunggal, Pokok-Pokok Outsourcing. Jakarta: Harvarindo, 2013.

[5] A. N. Ompusunggu and L. Sitorus, "Sistem Pendukung Keputusan Seleksi Penerimaan Asisten Praktikum menggunakan Metode Fuzzy Tsukamoto," Means (Media Inf. Anal. dan Sist., vol. 3, no. 2, pp. 185-189, 2018.

[6] J. Simarmata, T. Limbong, M. Aritonang, and S. Sriadhi, "Sistem Pendukung Keputusan Pemilihan Guru Bidang Studi Komputer Menggunakan Metode Simple Additive Weighting (SAW)," CESS (Journal Comput. Eng. Syst. Sci., vol. 3, no. 2, pp. 186-190, 2018, doi: https://doi.org/10.24114/cess.v3i2.10400.

[7] M. Badaruddin, "Sistem Pendukung Keputusan Penilaian Kinerja Karyawan Menerapkan Kombinasi Metode Simple Additive Weighting (SAW) dengan Rank Order Centroid (ROC)," J. Media Inform. Budidarma, vol. 3, no. 4, pp. 366-370, 2019, doi: http://dx.doi.org/10.30865/mib.v3i4.1508.

[8] Dixsen and D. Oktarina, "Sistem Pendukung Keputusan Kinerja Karyawan Menggunakan Metode Topsis dan SAW," J. Mhs. Apl. Teknol. Komput. dan Inf., vol. 2, no. 1, pp. 9-12, 2020.

[9] A. Darmawan and E. Purwaningsih, "Sistem Pendukung Keputusan Penilaian Kinerja Karyawan Dengan Metode Simple Additive Weighting Pada PT. Anggada Perkasa Tehnik," Informatics Educ. Prof., vol. 4, no. 1, pp. 23-32, 2019.

[10] P. S. Sukanto, "Sistem Pendukung Keputusan Penilaian Kinerja Karyawan PT Harjamukti Jaya Mandiri Menggunakan Metode Simple Additive Weighting," J. Tek. Inform. dan Sist. Inf., vol. 5, no. 1, pp. 109-118, 2018.

[11] A. K. Rahman and I. G. A. Suwartane, "Rancang Bangun Sistem Pendukung Keputusan Penilaian Karyawan Terbaik Dengan Metode Tehcnique For Order Preference By Similarity To Ideal Solution (Topsis) Berbasis Web," J. ikraith-teknologi, vol. 4, no. 1, pp. 22-31, 2020.

[12] A. Yunus, "Menguatkan Akar Filosofis Bumn Dalam Arus Industrialisasi: Kritik Terhadap Basis Pemikiran Era Revolusi Industri," J. Jurisprud., vol. 9, no. 1, pp. 17-38, 2019, doi: 10.23917/jj.v9i1.8092.

[13] Kadir, Statiska Terapan: Konsep, contoh dan Analisis data dengan program SPSS/ Lisler dalam penelitian. Jakarta: PT Rajawali Pers, 2015.

[14] D. Nofriansyah and S. Defit, Multi Criteria Decision Making (MCDM): pada sistem pendukung keputusan. Yogyakarta: Deepublish, 2017.

[15] S. Mahulae and T. Limbong, "Implementasi Metode Simple Additive Weighting dalam Penentuan Guru untuk diusulkan Sertifikasi," MEANS (Media Inf. Anal. dan Sist., vol. 4, no. 1, pp. 58-63, 2019.

[16] L. Budiman, S. Saori, R. N. Anwar, F. Yuga, and M. Pangestu, "Analisis Pengendalian Mutu Di Bidang Industri Makanan," J. Inov. Penelit., vol. 1, no. 10, pp. 2185-2190, 2021.

[17] E. R. Siagian. and B. Nadeak, "Implementasi Metode Simple Additive Weighting dalam Penerimaan Tenaga Medis/Kesehatan," J. Tek. Inform. Unika St. Thomas, vol. 4, no. 1, pp. 168-177, 2019. 
BINA INSANI ICT JOURNAL ISSN: 2355-3421 (Print) ISSN: 2527-9777 (Online); 166 - 175

[18] M. Takrim and R. H. Mikkael, "Pengaruh Kompetensi Dosen, Motivasi, dan Lingkungan Belajar terhadap Prestasi Belajar Mahasiswa pada Mata Kuliah Bahasa Inggris," Econ. Digit. Bus. Rev., vol. 1, no. 2, pp. 100-111, 2020, doi: https://doi.org/10.37531/ecotal.v1i2.14. 